\title{
Polyherbal Natural Hand Sanitizer Formulation and Evaluation
}

\author{
VIJAYA B. SURWASE, MANASI M. SAVALE, RANJIT S. JADHAV, AKSHAYKUMAR \\ B. KADAM , PRADNYA P. SHINDE. \\ Student, Student, Student, Student, Student.
}

vijayabsurwase@gmail.com, manasisavale9898@gmail.com, ranjitjadhav705@gmail.com, akshaykadam0223@gmail.com

\begin{abstract}
:
Making a poly herbal hand sanitizer's major purpose is to increase "hand hygiene." In the prevention, control, and reduction of hospital-acquired infections, hand hygiene is a key principle and practise. The plants were validated using fresh Azadirachta indica and Tridax procumbens leaves.The leaves were cleaned, dried in the shade, and used for future research. Using the Soxhlate equipment and hydroalcoholic solvent extraction, several phytochemicals were extracted, and the recovered phytochemicals were qualitatively examined before being evaluated for antibacterial activity. This herbal extract blend was used to make hand sanitizer.

Herbal hand sanitizer was evaluated using microorganism suspensions (Bacteria- E. coli, Staphylococcus aureus), which showed that herbal hand sanitizer is more efficient than commercial synthetic hand sanitizer in reducing the number of germs on the hands. The increased antibacterial activity and efficacy of these plant extracts can be exploited to create herbal hand sanitizers on a commercial scale. When the ingredients are mixed together, they form a hand sanitizer.
\end{abstract}

Keywords: Antimicrobial Activity, Azadirachta indica, Tridax procumbens, Hand Hygiene, Herbal Sanitizer, Hydroalcoholic Extraction.

\section{INTRODUCTION:}

One of the most important scientific and religious beliefs is to wash hands before eating. This is to keep dangerous bacteria out of the body and from creating infectious diseases. The uncleanliness of both the patient's and hospital staff's hands is to blame for the majority of hospital-acquired infections. The 
medical council and the World Health Organization have provided clear recommendations to use the approved hand sanitizers available at the hospital to clean hands. The majority of nosocomial infections, including as gastrointestinal and respiratory infections, are caused by poor hand cleanliness. As a result, disinfecting hands with clean water or wearing gloves is crucial.

However, providing safe drinking water and gloves, which are exclusively available in hospitals, is not always practicable. Hand sanitizers are the greatest and most accessible form of hand disinfection since they can be conveniently placed in hospitals, labs, restaurants, and toiletries ${ }^{[1,2]}$.Staphylococcus aureus and Escherichia coli are two prominent opportunistic bacteria that cause hospital-acquired illnesses. Pseudomonas aeruginosa and E. coli.

The most popular method of hand disinfection is to wash them with clean water. However, because the water used may not be safe at all times, soap and detergents have been added in addition to the water.Hand sanitizers that claim to have high bactericidal activity and are safe to use have recently been introduced to the market. Both alcohol-based and non-alcohol hand sanitizers are available on the market. The alcohol-based hand sanitizer claims to remove $99.99 \%$ of bacteria, including the most resistant strain.

Hand sanitizers come in liquid, foam, and easy-to-apply gel formulations that may be applied to the palm of the hand and rubbed over all surfaces of the hands and fingers until they are dry. The product is frequently utilised by doctors, surgeons before and after surgery, pathologists, and researchers, as well as restaurants, toiletries, and other businesses.Hand sanitizer is also available in the laboratories of medical and applied medical science institutions, which students use after each practical lesson.The goal of this study was to create a hand sanitizer formulation utilising extracts of Azadirachta indica and Tridax procumbens, as well as to test the extracts' antibacterial effectiveness against common bacteria that cause nasocomial illnesses.Additionally, to assess the stability and phytochemical properties of the created formulations in order tostandardise and commercialise them.

\section{MATERIALS AND METHODS}

\section{Collection, Drying of Plant Material-}

Mature plants of Azadirachta indica and Tridax procumbens were used for this preparation and were collected by in sangli district. The leaves were collected, dried in shade, coarsely powdered and wellstoppered container. The dried material of Azadirachta indica and Tridax procumbens was then used further work.

\section{Method for extraction of Azaridacta indica extract :}

Plant extract preparation In a Soxhlet extractor, $10 \mathrm{~g}$ of powdered leaves were extracted sequentially with $100 \mathrm{ml}$ of methanol at $40-50^{\circ} \mathrm{C}$ until the extract was clear. The extracts were evaporated to dryness and kept in a refrigerator at $4^{\circ} \mathrm{C}$ for future usage as pasty form extracts. ${ }^{3}$ 


\section{Method for extraction of Tridax procumbens extract:}

Extraction was carried out by soxhlet apparatus and it's working on steam distillation process. The powdered leaves of $50 \mathrm{gm}$ were added on $400 \mathrm{ml}$. of ethanol, the working temperature was maintained at $40 \square \mathrm{C}$ and distillate for 1 hour. Once the distillation started the sample start boiling within 5 min and vapour are formed. The vapour is cooled down with the help of condensed. The condensed material was collected on the other side of setup. After completion, the extraction process, the solvent and extractor were placed rotary evaporator to evaporate the solvent ${ }^{[3]}$.

\section{Preliminary antimicrobial screening of the extracts}

The presence of active chemical elements such as alkaloids, glycosides, terpenoids, and steroids, flavonoids, reducing sugars, triterpenes, phenolic compounds, and tannins was determined using phytochemical testing. All leaf extracts were tested for antibacterial activity using the dilution technique against E. coli, S aureus, B. subtilis, and P. aeruginosa.The extracts which exhibited maximum activity were selected for the formulation ${ }^{[4]}$

\section{Method of Preparation of Hand Sanitizer:}

Extracts and other ingredients were accurately weighed. The quantity of denatured alcohol and water were separated in four equal quantities. In each part of denatured alcohol, both extracts, emollient and preservative were uniformly mixed using mechanical stirrer. To this four-alcoholic mixture, four equally separated quantities of deionized water were added and mix until the mixture was uniform. With continuous stirring, the solution of both the extracts was mixed together and the solution of emollient was also added to this, which is followed by the addition of preservative solution. These solutions were uniformly mixed, and emulsifier was added. After ensuring the solutions are mixed properly to one another perfume was added ${ }^{[5,6,7]}$. The composition is given in Table no.1

Table 1. Composition of hand sanitizer

\begin{tabular}{llccr}
\hline Sr. No. & Ingredients & $\begin{array}{c}\text { Quantity } \\
\text { given (\%) }\end{array}$ & $\begin{array}{c}\text { Quantity } \\
\text { taken } \mathbf{( g m} / \mathbf{m l})\end{array}$ & Uses \\
\hline 1 & Eucalyptus extract & 1.5 & 0.7 & Antimicrobial \\
2 & Neem extract & 1.5 & 0.7 & Antimicrobial \\
3 & Sorbitol & 2.30 & 2.12 & Emollient \\
4 & Polysorbate 20 & 0.50 & 0.48 & Emulsifier \\
5 & Methyl paraben & 0.50 & 0.3 & Preservative \\
6 & Alcohol denatured & 62.0 & 15.5 & Antibacterial \\
7 & Deionized water & 30.0 & 10 & Vehicle \\
8 & Perfume & Q.S. & Q.S. & Fragrance \\
\hline
\end{tabular}




\section{Evaluation of physicochemical parameters of the hand sanitizer:}

The physicochemical characteristics of hand sanitizer such as clarity, colour, odour, were determined as per Indian Pharmacopoeial Procedures and $\mathrm{pH}$ was determined using digital $\mathrm{pH}$ meter. The foam height, foam retention, alcohol insoluble matter was determined ${ }^{[5]}$.

\section{Stability of formulation:}

Liquid sanitizer was allowed to stand at 37oC for two months. The stability of liquid sanitizer was observed during this period. The sample which was stable liquid after standing was indicated as stable and the sample in which precipitation were caused; then liquid was said to be as unstable.

\section{Antimicrobial testing of the prepared formulations:}

The screening of antibacterial activity of the formulation against pathogens was performed using disc diffusion method. Nutrient agar media was prepared, sterilized and aseptically spread on four sets of Petri plates which were previously marked as formulation coding. Microorganisms used were Staphylococcus aureus, Escherichia coli, B.subtilis, P.aeruginosa. The plates were inoculated with microorganism suspension and incubated at $37^{\circ} \mathrm{C}$ for $24 \mathrm{~h}$. Next day filter paper discs loaded with alcohol based herbal hand sanitizerand synthetic hand sanitizer were placed in the respectively marked plates. It was taken care that the sterile discs completely absorb the formulation. After $24 \mathrm{~h}$ test results were observed to determine the efficacy of formulations in terms of zone of inhibition of microorganism. Higher the zone of inhibition, the more effective is the test formulation ${ }^{[1,2,6] \text {. }}$

\section{RESULTS AND DISCUSSION :}

Table no. 2. Preliminary phytochemical sscreening of Azadirachta Indica

\begin{tabular}{|c|c|c|}
\hline Sr.no & Test & Result \\
\hline 1 & Phenolic compound & + \\
\hline 2 & Terpenoid & - \\
\hline 3 & Triterpenes & - \\
\hline 4 & Tannins & - \\
\hline 5 & Saponins & + \\
\hline 6 & Steroids & + \\
\hline 7 & Flavonoids & \\
\hline
\end{tabular}

Absent:(-) Present:(+) 
Table no. 3. Preliminary phytochemical screening of Eucalyptus globulus

\begin{tabular}{|l|l|l|l|}
\hline Sr.no & Plant constituents & Test & result \\
\hline 1 & Alkaloids & $\begin{array}{l}\text { Dragendroff's,Hager's, } \\
\text { Mayer's, Wagner's }\end{array}$ & - \\
\hline 2 & tannin & $\begin{array}{l}\text { Ferric Chloride,Leadacetate,Pot. } \\
\text { Dichromate }\end{array}$ & + \\
\hline 3 & Terpenoids & Phenol & + \\
\hline 4 & Flavonoids & Shinoda Test & + \\
\hline 5 & saponins & Foam Test & + \\
\hline 6 & Glycosides & $\begin{array}{l}\text { Anthraquinone glycosides, Cumarin } \\
\text { test }\end{array}$ & - \\
\hline 7 & sterols & $\begin{array}{l}\text { Salkowaski,Libermann'sLibermann- } \\
\text { Burchard }\end{array}$ & + \\
\hline
\end{tabular}

Absent: (-) Present: $(+)$

Table no.4. Antibacterial activity of Azadirachtaindica and Tridax procumbens (Minimum Inhibitory Concentration):

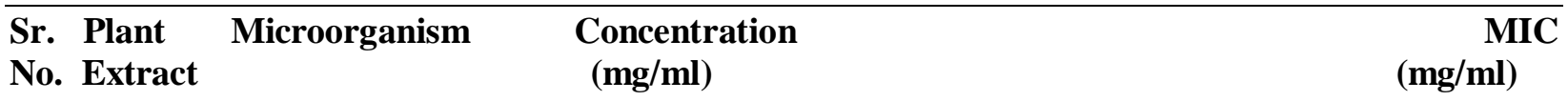

\begin{tabular}{llllllllllllll}
\hline & & & 50 & 25 & 12.5 & 6.2 & 53.125 & 1.56 & 0.78 & 0.39 & 0.2 & 0.1 & \\
1 & Azadirachta & S.aureus & ++ & + & + & - & - & - & - & - & - & - & 3.12
\end{tabular}

Indica

$$
\begin{array}{lllllllllll}
\text { E. Coli } & ++ & + & + & + & - & - & - & - & - & - \\
\text { B. subtilis }++ & + & + & - & - & - & - & - & - & - \\
\text { P. aeruginosa } & + & + & - & - & - & - & - & - & - & - \\
\end{array}
$$

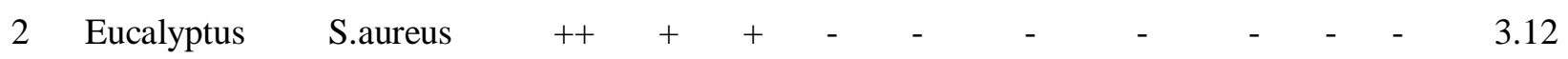

Globules

$\begin{array}{lllllllllll}\text { E. coli } & + & + & + & - & - & - & - & - & - & - \\ \text { B. subtilis } & ++ & + & - & - & - & - & - & - & - & - \\ \text { P. aeruginosa } & + \\ \text { Turbidity: Present (+) Absent (-) }\end{array}$


Table no.5. Physicochemical parameters of formulations

\begin{tabular}{|l|l|l|l|}
\hline Sr.no & Parameters & HF1 & HF2 \\
\hline 1 & Colour & Dark green & Dark green \\
\hline 2 & Odur & Aromatic & Aromatic \\
\hline 3 & Apperance & Liquid & Liquid \\
\hline 4 & PH & 6.40 & 6.00 \\
\hline 5 & Foam height & 4.0 & 4.5 \\
\hline 6 & Foam retention & 1.4 & 1.2 \\
\hline 7 & Alcohol insolublematter & 2.3 & 3.2 \\
\hline 8 & Stability & stable & stable \\
\hline
\end{tabular}

Table no.6. Antimicrobial screening of the prepared formulation

\begin{tabular}{|l|l|l|l|l|l|}
\hline \multirow{3}{*}{ Organism } & \multicolumn{6}{|c|}{ Zone of Inhibition (Diameter in mm) } \\
\cline { 2 - 6 } & \multicolumn{4}{|c|}{ Conc. Of Drug in $\mathbf{~} \mathbf{~ g o m l}$} \\
\cline { 2 - 6 } & $\mathbf{8 0 0}$ & $\mathbf{6 0 0}$ & $\mathbf{4 0 0}$ & $\mathbf{2 0 0}$ & Std \\
\hline & & & & & \\
\hline E. coli & 32 & 30 & 36 & 30 & 34 \\
\hline S. aureus & 34 & 28 & 30 & 36 & 32 \\
\hline B. subtilis & 30 & 36 & 28 & 32 & 30 \\
\hline P.aeruginosa & 34 & 32 & 30 & 28 & 36 \\
\hline
\end{tabular}

Fig.1: Antimicrobial study of prepared formulation against various pathogens

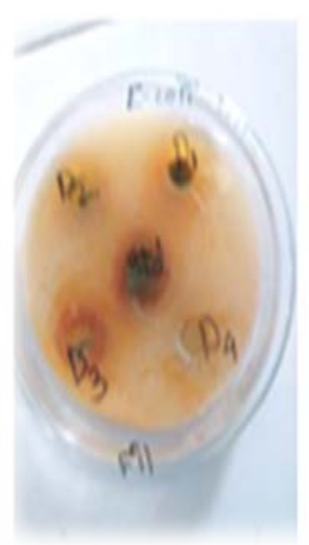

E. coli

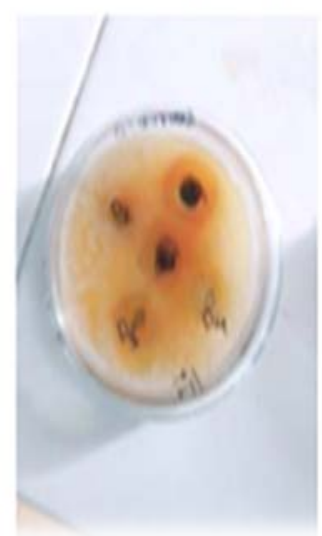

S. aureus

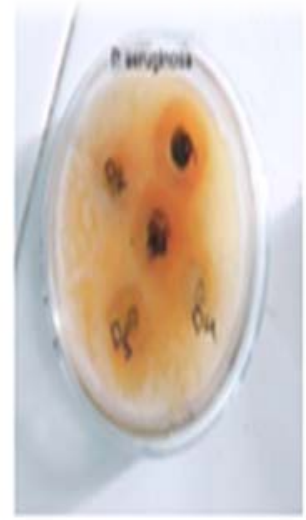

B.Subtilis

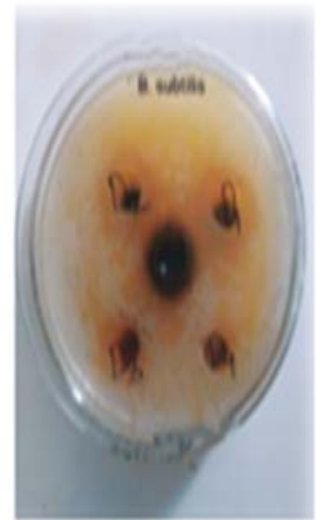

P.aeruginosa 
The major goal of this study was to create a herbal hand sanitizer and see if the formulation has antibacterial action against the typical bacteria that cause nasocomial infections. At concentrations starting at $400 \mathrm{~g} / \mathrm{ml}$, the produced herbal hand sanitizer exhibited substantial effectiveness against four bacterial species (E. coli, B.subtilis, P.aeruginosa, and S.aeruginosa). In contrast to the conventional reference, the significance was determined to be higher. Free radical scavenging, antibacterial, antiinflammatory, and analgesic activities have been attributed to the composition (Azadirachta indica and Eucalyptus globulus). To acquire a broad range action of the test medication, more concentrations may be required. The alcohols have high germicidal action against vegetative bacteria, fungus, and many viruses, and their antibacterial action is based on microorganism protein denaturation. Mycobacteria (the bacteria that are the most resistant to disinfection) and multidrug-resistant diseases are particularly susceptible to alcohol sanitizers.

Hand rubs with alcohol are 100 times more efficient against viruses than any other method of hand cleansing. Sanitizers have several benefits over non-alcoholic hand disinfectants, such as the fact that rubbing sanitizers on both hands and waiting for them to evaporate takes just 15 to 30 seconds. Whereas hand disinfectants need vigorous friction, washing with water, and drying with a towel, forceful friction, rinsing with water, and drying with a towel are not required.

\section{CONCLUSION:}

Hands are the most common mode of transmission of pathogens to patients and proper hand hygienecan prevent health care-associated infections and the spread of antimicrobial resistance. Scientific evidence and ease of use support of alcohol-based hand sanitizers during patient care. It may be concluded that Herbal Hand Sanitizer has a significant anti-microbial effect on the specified microorganisms except Ps. aeruginosa and S. cerevisiae. Thus, there is immense potential in establishing the use of antimicrobial herbal products as a measure to control the multidrug resistant microbes as well as check their spread through hands from one geographical region to another.

\section{REFERENCES:}

1. Otokunefor, K; Princewill, I, Evaluation of antibacterial activity of hand sanitizers - an in vitro study, J. Appl. Sci. Environ. Manage. Dec, 2017, Vol. 21 (7) 1276-1280.

2. Dr. Yousuf Adam Ali, to study the effect of hand sanitizers used in kingdom of saudiarabia against the common bacterial pathogens, International Research Journal of Natural and Applied Sciences Volume-2, Issue-2 (February 2015),17-28.

3. Kokate CK, Purohit AP and Gokhale SB. Pharmacognosy, 51st Ed., NiraliPrakashan, Pune, 2015, P. 1.1,14.41-14.43.

4. Seerangaraj V., Suruli K, Konda Mani Saravanan, Preliminary Phytochemicals Screening, Antibacterial potential and GC-MS Analysis of medicinal plants extracts, Article in journal of pharmaceutical sciences. April 2016.

5. Zeeshan A., Salma K., Formulation and Evaluation of Poly Herbal Hand Sanitizer, Article in Inertnational Research Journal of Pharmacy, September 2016. 
6. P.P Sharma, Cosmetics -Formulation, Manufracting and Quality Control IV edition, Vandana Publication, Delhi ,2008 P.143-148.

7. Sanju N., Arun N., Roop K, Cosmetic Technology, I edition, Brila Publication, Delhi, 2009-10 P.115-117.

8. Rangari VD. Pharmacognosy and Phytochemistry, Vol I, 2nd Ed., Career Publications, Nashik, 2008, P. 204,346.

9 Ali M. Pharmacognosy and phytochemistry, Vol l, CBS Publishers and Distributors, New Delhi, 2009, P.462- 463, 676-683.

10 Khadabadi SS, Deore SL, and Baviskar BA. Experimental Pharmacognocy 1st Ed., NiraliPrakashan, Pune P. 3.1-3.8.

11 Tortora, F.C, Microbiology an Introduction IX edition Pearson Publication. P.602.

12 Dr. Suresh Jain, Professor Vipin Saini, Dr. Naitikkumar, A Practical Book on Calibration Analytical Instruments III edition 2015, NiraliPrakashan. P. 10.

13 Chandrakant Kokare, Pharmaceutical Microbiology, Experiments and Techniques, Career Publication II Edition. P.84-86, 138-139. 